\title{
CONHECIMENTO, PRÁTICAS E ATITUDES EM RELAÇÃO AO DIAGNÓSTICO DO CÂNCER DE BOCA NA VISÃO DA POPULAÇÃO
}

Ana Paula Sapata MOLINA; Mariana Gomes RIBEIRO; Josiane Aparecida da SILVA; Cassius Carvalho TORRES-PEREIRA

Este estudo objetivou identificar o grau de conhecimento sobre o câncer bucal em uma amostra populacional da cidade de Curitiba-PR. Um questionário desenvolvido para este projeto foi aplicado a 1000 indivíduos por 3 examinadores. A amostra foi estratificada pelos bairros do município, com abordagem aleatória, dentre os transeuntes, em regiões de maior aglomeração urbana. Os resultados foram tabulados de maneira descritiva e os percentuais calculados para cada questão proposta no questionário, incluindo dados demográficos tais como idade, nível de escolaridade e renda. Aproximadamente $97 \%$ dos entrevistados responderam acreditar que o câncer pode ocorrer na boca. Por outro lado, 27\% não sabiam identificar quaisquer sinais ou sintomas desta doença. Dentre os fatores de risco $34 \%$, $8 \%$ e $1 \%$ apontaram tabagismo, etilismo e exposição solar, respectivamente, como os principais causadores do câncer de boca. Os resultados_sugerem que a população estudada apresenta um nível maior de conhecimento sobre a possibilidade de malignização da mucosa bucal do que o verificado em outros estudos. Os sinais e sintomas mais comuns do câncer da boca assim como os principais fatores de risco conhecidos não foram, entretanto, respostas freqüentes quantitativamente, sugerindo que maiores esforços são necessários para conscientização da população sobre a doença e principais características. 